\title{
Analysis of Network Characteristics to Assess Community Capacity of Latino-Serving Organizations in Philadelphia
}

\author{
Nishita Dsouza • Elizabeth McGhee-Hassrick • Kristin Giordano • Chris Friedman • \\ Yoshiaki Yamasaki • Cristina Perez • Omar Martinez • Amy Carroll-Scott • Ana P. \\ Martinez-Donate (1)
}

Accepted: 22 February 2021 / Published online: 15 March 2021

(C) The New York Academy of Medicine 2021

\begin{abstract}
Latino immigrants are disproportionately impacted by substance use, HIV/AIDS, domestic violence, and mental health (SAVAME). The burden of these syndemic conditions is influenced by limited access to health and social services to prevent and treat these conditions. The syndemic nature of these factors necessitates an integrated, coordinated approach to address them simultaneously. We analyzed characteristics of Latino-serving organizations in Philadelphia, PA, that provide SAVAME-related health and/or social services, and their interorganizational collaborations to meet the
\end{abstract}

N. Dsouza - E. McGhee-Hassrick · A. Carroll-Scott •

A. P. Martinez-Donate $(\bowtie)$

Drexel University, Nesbitt Hall Room 458, 3215 Market St NW, Philadelphia, PA 19104, USA

e-mail: apm78@drexel.edu

K. Giordano

Equal Measure, Philadelphia, PA, USA

C. Friedman

Children's Hospital of Philadelphia, Philadelphia, PA, USA

Y. Yamasaki

The Philadelphia AIDS Consortium, Philadelphia, PA, USA

C. Perez

Women Organized Against Rape, Philadelphia, PA, USA

O. Martinez

Temple University, Philadelphia, PA, USA needs of Philadelphia's Latino communities. We surveyed Latino-serving organizations $(N=43)$ identified through existing resource directories and key informants. Network analyses identified patterns and density of collaborative ties (i.e., referrals, administrative, or planning/advocacy) across organizations and characterized these ties by type of service. Density (expressed as percent of all possible ties) revealed a higher referral rate (40\%) than administrative $(29 \%)$ or planning $(26 \%)$ coordination. Network sociograms display clusters of providers by geography. Examination of bonding (within-group) ties revealed comparable perceptions of high value among both South/Center Philadelphia (57\%) and in North Philadelphia providers (56\%), but bridging (between-group) ties suggest lower levels of high-value perceptions (24\%). No evident clustering by type of service based on syndemic factor was observed. Density of bridging across types of providers was highest for referrals (38\%) followed by planning $(23 \%)$ and administrative coordination (20\%). Interventions to promote collaboration between providers should focus on facilitating administrative and planning collaborations that leverage existing capacity of the network. Given the syndemic nature of these conditions, greater collaboration between providers of complementing SAVAME services is imperative.

Keywords Culturally competent care · Latino health . Immigrant health · Urban health · Philadelphia . Syndemic · Geography · Referral and consultation . Cross-sector collaboration 


\section{Introduction}

Latino populations in the USA are disproportionately affected by substance use, HIV/AIDS, domestic violence, and mental health, also known as "SAVAME" [1]. Significant evidence documents the synergistic nature of these conditions. For example, substance use is associated with higher HIV transmission [2], poor mental health [3], and violence victimization; these relationships are also bidirectional, with untreated mental health conditions associated with increased HIV risk behavior [2], substance use [4], and violent victimization [1, 5]. Similarly, interpersonal violence, a highly documented form of violence victimization in this population, is also a risk factor for HIV infection and a known cause of stress and trauma [6].

These interactions can be understood through a syndemic orientation, a socioecological model about clustering of health conditions in populations simultaneously experiencing poor physical and social conditions [7]. Understanding networks and collaboration between Latino-serving health and social services organizations is essential to mitigating the impact of these syndemic factors.

Philadelphia has a rapidly growing Latino population [8]. Census estimates indicate that Latinos make up $15.2 \%$ of the city's population $(240,778$ out of $1,584,064$ people) [9]. Organizations serving Latinos concentrate in North Philadelphia, which has a larger proportion ofLatino residents (most of whom are of Puerto Rican origin) and South Philadelphia, which has a smaller but fast-growingLatino community (most of whom are of Mexican origin) [10]. For many of these organizations (54\%, according to a recent survey), Latino clients represent more than half of their clients [11]. Documentation of the SAVAME syndemic in Philadelphia shows Latinos have the highest rate of new HIV and mental health diagnoses and the second highest rate of binge drinking and opioid-related mortality compared to other racial and ethnic groups [12]. Service integration is necessary to address SAVAME conditions. However, existing anecdotal evidence and limited research suggest that SAVAME-related services are insufficient, with providers siloed geographically and by service type [13].

Understanding the network structure of institutions serving Latino communities can inform policies or programs to ameliorate health disparities [14]. Therefore, we examined the Latino-serving organizational landscape of SAVAME-related service providers in Philadelphia and analyzed variations in collaborative ties by geography and SAVAME factor.

\section{Methods}

Theoretical Foundation

Our interest in interorganizational collaborations is informed by a social ecological framework, which recognizes individual, interpersonal, community, cultural, and broader structural and policy factors as determinants of health behaviors and outcomes $[15,16]$. Within this framework, community-based organizations, and the extent to which these organizations collaborate, represent important factors impacting community health [17].

Our use of network analysis to examine interorganizational relationships relies on resource exchange theory [18]. In this theory, an exchange relation consists of voluntary transfer of resources between two or more organizations for mutual benefit. We also draw from Bolland and Wilson's model of integrative coordination [19], which considers both density and pattern of organizational linkages. This model differentiates three types of linkages: [1] service delivery, or referrals, [2] administration, and [3] planning. Examination of these ties depicts different patterns of interorganizational relationships and levels of coordination. Lastly, syndemic theory posits that aligned, coordinated services, rather than siloed care networks, are essential to target relevant SAVAME determinants [20]; therefore, interorganizational ties serve as indicators of an organizational network's capacity to achieve shared goals [18].

\section{Survey Development and Administration}

This study is part of an ongoing mixed-methods research project to inform community-wide interventions to reduce the disproportionate impact of SAVAME on Philadelphia Latino communities. Public health researchers from Philadelphia-based universities and community members from Latino-serving agencies developed a roster of 43 Latino-serving organizations. Included organizations provide SAVAME-related health, educational, legal, or social services to adult Latino immigrants from any Latin American country (e.g., Mexicans, Central Americans, South Americans) or US citizens from Puerto Rico living in Philadelphia. 
We developed a cross-sectional survey with questions about organizational demographics, perceptions of access to SAVAME-related services, and questions about collaboration with other Latino-serving institutions and refined it based on community partners' feedback.

Surveys were administered electronically via Qualtrics (SAP, Walldorf, Germany) from October 2018 through March 2019. Research staff contacted Latino-serving organizations by phone and email, requesting completion of the survey by director-level staff or individuals with significant institutional knowledge. Final contact attempts were made via a mailed letter from the principal investigator. Respondents received a $\$ 15$ gift card incentive for completion.

The survey included network (i.e., relational) questions. We displayed all 43 Latino-serving organizations and asked respondents about three types of relationship ties between these and their own organization: referral, administrative coordination, and planning [19]. Definitions and examples for these types of collaborations were provided in the questionnaire. Referrals were defined as sharing information or directing to other agencies' services, making appointments, or assisting with intake, etc. Administrative coordination was defined as jointly operating programs with another organizations, sharing staff, facilities, or training opportunities, etc. Planning was defined as partnering on grant applications, agenda-setting conversations, or advocacy about relevant issues, etc. Respondents could check all that applied or "none." Organizations were also asked whether each organization listed was considered a "highly valuable resource for Latino immigrants in Philadelphia" or not. By examining density and pattern of these linkages, we gauged the degree to which a systemwide dialogue has emerged connecting and coordinating agencies/organizations who provide different, complementary, services to Latino immigrants. Such an interconnected system would be responsive to dynamic evolving needs of clients and the sociopolitical climate.

As an additional variable, we identified service location (North vs. South/Center Philadelphia) using publicly available information. We coded organizations with satellite sites at their primary location of service delivery.

Network Measures and Analyses

Organizational descriptive statistics were calculated using SPSS (IBM, Armonk, NY). We created four sociograms (visual network maps) in *ORA-LITE (Carnegie Mellon, Pittsburgh, PA): [1] referrals (self-reported referral activity between organizations); [2] administrative (self-reported administrative activity coordination between organizations); [3] planning (self-reported planning activity coordination between organizations); and [6] high value (perceptions of value as reported about other organizations in the network). Ties were configured differently based on type of network:

Referral and high-value networks: referral and high-value networks were asymmetrical, and directionality of ties was retained (i.e., indicating direction of client referrals or perceived value of an organization). As such, referral networks captured flows of care delivery within networks and value networks measured perceptions of value attributed by each organization about other organizations in the network.

Administrative and planning networks: administrative and planning networks were transformed into symmetrical matrices using the maximum symmetrizing method to convert the directed matrix of each network into undirected adjacency matrices $[21,22]$. Ties in these two networks were counted regardless of relationship directionality (i.e., if only one organization claimed to have an administrative collaboration with another, that maximum report was used to summarize the link between the two organizations).

We conducted social network analyses using *ORAPRO (Carnegie Mellon, Pittsburgh, PA), to determine density and reciprocity among bonding ties (i.e., connections between organizations of a similar type) and bridging ties (i.e., connections between organizations of a different type) for all four networks. We calculated overall density as percent of ties in the network compared to total possible number of ties (range 0-100). For high-value and referral networks, reciprocity was calculated as percent of mutual ties in the network compared to total possible number of mutual ties in the network (range 0-100). Each network was binary and self-loops were not included. High network density, along with high reciprocity (the degree to which "ties" between pairs of organizations are recognized by both organizations), indicate strongly connected networks [23]. 
Examining bonding ties and bridging ties improves understanding of interorganizational dynamics and existence of siloes [24]. Bonding ties among similar characteristics (e.g., location proximity or type of service offered by organizations) can maintain coordination. Bridging ties can help expand organizational reach and integrate provision and referral across locations or types of service. We examined bridging and bonding ties by location (e.g., bonding ties within North- and South/ Center-based organizations, and bridging ties between North- and South/Center-based organizations) and by syndemic factor(s) for which organizations provided services (e.g., examining bonding ties within domestic violence providers and bridging ties between domestic violence and mental health organizations).

Adjacency matrices and submatrices were created to calculate density and reciprocity measures for overall, bonding, and bridging networks. From the four overall adjacency matrices (high value, referral, administrative, planning), 6 bonding and 6 bridging submatrices were created for each network type. Each submatrix was binary and self-loops were not included. As stated, high-value and referral submatrices were asymmetrical and administrative coordination and planning submatrices were symmetrical. Reciprocity values were calculated for asymmetrical highvalue and referral subnetworks.

\section{Results}

\section{Organizational Demographics}

Of the 43 organizations identified, 31 participated, resulting in a survey response of $72.1 \%$ (Table 1). Eight organizations reported providing substance use services, five organizations reported providing HIV/AIDS services, nine organizations reported providing domestic violence services, and ten organizations reported providing mental health services (note: organizations can provide services for multiple factors). Over half (58\%) also offered related social services in addition to the core services provided.

\section{Network Characteristics}

Sociograms of referral, administrative, planning coordination, and high-value networks suggest much interconnection between organizations (Fig. 1). No visually evident clusters or unique nodes (e.g., brokers, or organizations that act as intermediaries between other organizations that would not otherwise be connected) emerged. However, organizations clustered geographically, such that South/Center Philadelphia and North Philadelphia providers were more interconnected within location. No evident clustering by syndemic factor was observed (Fig. 2).

Referrals The referral network was moderately dense, with $40 \%$ of all possible referrals present (Table 2). Reciprocity of referrals was also moderately dense, with $36 \%$ of all possible reciprocated referrals (i.e., bidirectional) present. Examination of geographical bonding ties revealed that North Philadelphia providers had a slightly higher density of referrals than South/Center Philadelphia providers (50\% vs. $43 \%)$. Reciprocity of bonding ties by location was comparable, with $43 \%$ of all possible reciprocated referrals present in North Philadelphia and $47 \%$ of all possible reciprocated referrals present in South/Center Philadelphia. Examination of syndemic factor-specific bonding ties showed higher referral rates among HIV/ AIDS (85\%) and domestic violence providers (64\%) when compared to mental health (36\%) or substance use $(52 \%)$ providers. Referrals were also more often reciprocated among HIV/AIDS (70\%) and domestic violence (59\%) providers as compared to mental health $(28 \%)$ or substance use $(38 \%)$ providers.

Administrative Collaborations Administrative ties were reported at a lower rate compared to referrals $(29 \%$ versus $40 \%$ referral rate; Table 2). Contrary to referrals, examination of bonding ties revealed that South/Center Philadelphia providers have a higher density of administrative coordination than North Philadelphia providers $(45 \%$ vs. $35 \%$ ). Reciprocity of administrative coordination was not estimated due to the assumption that if one organization reported collaborating with another for administrative purposes, the collaboration was reciprocal (i.e., symmetrizing of ties). Rates of administrative collaboration were also lower than referrals when examining bonding ties of syndemic providers within networks. Domestic violence providers had the highest rate of administrative coordination (53\%), followed closely by HIV/AIDS (50\%), and then mental health $(27 \%)$ and substance use (18\%).

Planning Collaborations Planning activity coordination occurred less frequently (26\%) than administrative coordination (29\%) or referrals (40\%; Table 2). Examination of bonding ties revealed North Philadelphia and South/Center Philadelphia providers have the same density 
Table 1 Organizational demographics of Latino-serving organizations in Philadelphia, 2018-2019 (N=31)

\begin{tabular}{|c|c|c|c|c|c|c|c|}
\hline & $\begin{array}{l}\text { All } \\
(N=31) \\
n(\%)^{2}\end{array}$ & $\begin{array}{l}\text { Domestic violence } \\
(N=9) \\
n(\%)\end{array}$ & $\begin{array}{l}\mathrm{HIV} \\
(N=6) \\
n(\%)\end{array}$ & $\begin{array}{l}\text { Mental health } \\
(N=10) \\
n(\%)\end{array}$ & $\begin{array}{l}\text { Substance use } \\
(N=9) \\
n(\%)\end{array}$ & $\begin{array}{l}\text { Legal }(\%) \\
(N=12) \\
n(\%)\end{array}$ & $\begin{array}{l}\text { Other }^{1} \\
(N=11) \\
n(\%)\end{array}$ \\
\hline \multicolumn{8}{|l|}{ Type of organization ${ }^{2,4}$} \\
\hline Non-profit (general) or $\mathrm{CBO}^{3}$ & $27(87.1)$ & $9(100.0)$ & $5(83.3)$ & $9(90)$. & $8(88.9)$ & $11(91.7)$ & $9(81.8)$ \\
\hline Healthcare organization & $8(25.8)$ & $2(22.2)$ & $4(66.7)$ & $3(30.0)$ & $5(55.6)$ & $1(8.3)$ & $6(54.5)$ \\
\hline Religious/spiritual organization & $4(12.9)$ & $0(0,0)$ & $0(0.0)$ & $0(0.0)$ & $1(11.1)$ & $3(25.0)$ & $0(0.0)$ \\
\hline Legal office/legal services & $4(12.9)$ & $2(22.2)$ & $0(0.0)$ & $0(0.0)$ & $0(0.0)$ & $4(36.4)$ & $1(9.1)$ \\
\hline Educational institution & $2(6.5)$ & $0(0.0)$ & $0(0.0)$ & $1(10.0)$ & $1(11.1)$ & $1(8.3)$ & $1(9.1)$ \\
\hline Government entity & $2(6.5)$ & $1(11.1)$ & $1(16.7)$ & $1(10.0)$ & $2(22.2)$ & $0(0.0)$ & $1(9.1)$ \\
\hline Other social services & $4(12.9)$ & $1(11.1)$ & $2(33.3)$ & $1(10.0)$ & $1(11.1)$ & $0(0.0)$ & $3(27.3)$ \\
\hline \multicolumn{8}{|l|}{ Organization location } \\
\hline North Philly & $18(58.1)$ & $4(44.4)$ & $4(66.7)$ & $5(50.0)$ & $6(66.7)$ & $5(41.7)$ & $5(45.5)$ \\
\hline South/Center Philly & $13(41.9)$ & $5(55.6)$ & $2(33.3)$ & $5(50.0)$ & $3(33.3)$ & $7(58.3)$ & $6(54.5)$ \\
\hline \multicolumn{8}{|l|}{ Types of services provided ${ }^{4}$} \\
\hline Other social/supportive services & $18(58.1)$ & $5(55.6)$ & $3(50.0)$ & $5(50.0)$ & $6(66.7)$ & $8(66.7)$ & $6(54.5)$ \\
\hline Immigration/legal/advocacy services & $12(28.7)$ & $5(55.6)$ & $2(33.3)$ & $3(30.0)$ & $1(11.1)$ & $12(100)$ & $4(36.4)$ \\
\hline Substance use & $9(29.0)$ & $4(44.4)$ & $5(83.3)$ & $4(40.0)$ & $9(100)$ & $1(8.3)$ & $6(54.5)$ \\
\hline HIV/AIDS & $6(19.4)$ & $3(33.3)$ & $6(100)$ & $1(10.0)$ & $5(55.6)$ & $2(16.7)$ & $6(54.5)$ \\
\hline Domestic violence & $9(29.0)$ & $9(100)$ & $3(50.0)$ & $4(40.0)$ & $4(44.4)$ & $5(41.7)$ & $5(45.5)$ \\
\hline Mental health & $10(32.3)$ & $4(44.4)$ & $1(16.7)$ & $10(100)$ & $4(44.4)$ & $3(25.0)$ & $4(36.4)$ \\
\hline Other health services & $11(35.5)$ & $5(55.6)$ & $6(100.0)$ & $4(40.0)$ & $6(66.7)$ & $4(33.3)$ & $11(100)$ \\
\hline
\end{tabular}

${ }^{1}$ Other refers to the provision of other health services for conditions outside of the SAVAME syndemic

${ }^{2}$ Percentages were calculated with the valid percentage. Missing data ranges from 1 to 2

${ }^{3}$ Community-based organization

${ }^{4}$ Categories are not mutually exclusive. Organizations are able to report more than 1 category, making the total sum larger than the final number of survey respondents

of planning coordination (32\%). Reciprocity of planning collaboration was not estimated due to the assumption that if one organization reported collaborating with another for planning purposes, the collaboration was reciprocal (i.e., symmetrizing of ties). By syndemic factor addressed, domestic violence organizations had the highest rate of planning activity coordination (53\%), followed by HIV/AIDS providers $(40 \%)$, and then substance use (32\%) and mental health $(27 \%)$ providers.

Perceptions of High Value Density of the network revealed $50 \%$ of "high-value" ties were present, indicating some level of professional trust among organizations (Table 2). The reciprocity of this network was $58 \%$, indicating that of those high-value ties, $42 \%$ were unidirectional (i.e., organization $X$ considered organization $Y$ to be highly valuable, but $Y$ did not consider $X$ as such). Examination of bonding ties revealed comparable perceptions of high value among both South/Center Philadelphia (57\%) and in North
Philadelphia providers (56\%). Reciprocity of geographical ties indicates that providers in North Philadelphia were less likely to reciprocate perceptions of high value (38\%) compared to providers in South/Center Philadelphia (45\%). Consistent with referral patterns, perceptions of high value as indicated by syndemic factor-specific bonding ties were highest among HIV/AIDS (75\%) and domestic violence providers $(71 \%)$ when compared to mental health $(56 \%)$ or substance use $(61 \%)$ providers. Similarly, perceptions of high value were also more often reciprocated among HIV/ AIDS (67\%) and domestic violence (55\%) providers as compared to mental health (39\%) or substance use $(36 \%)$ providers.

Collaboration across Geography (Bridging Ties between North and South/Center Philadelphia)

Bridging ties between providers in North Philadelphia versus South/Center Philadelphia were 

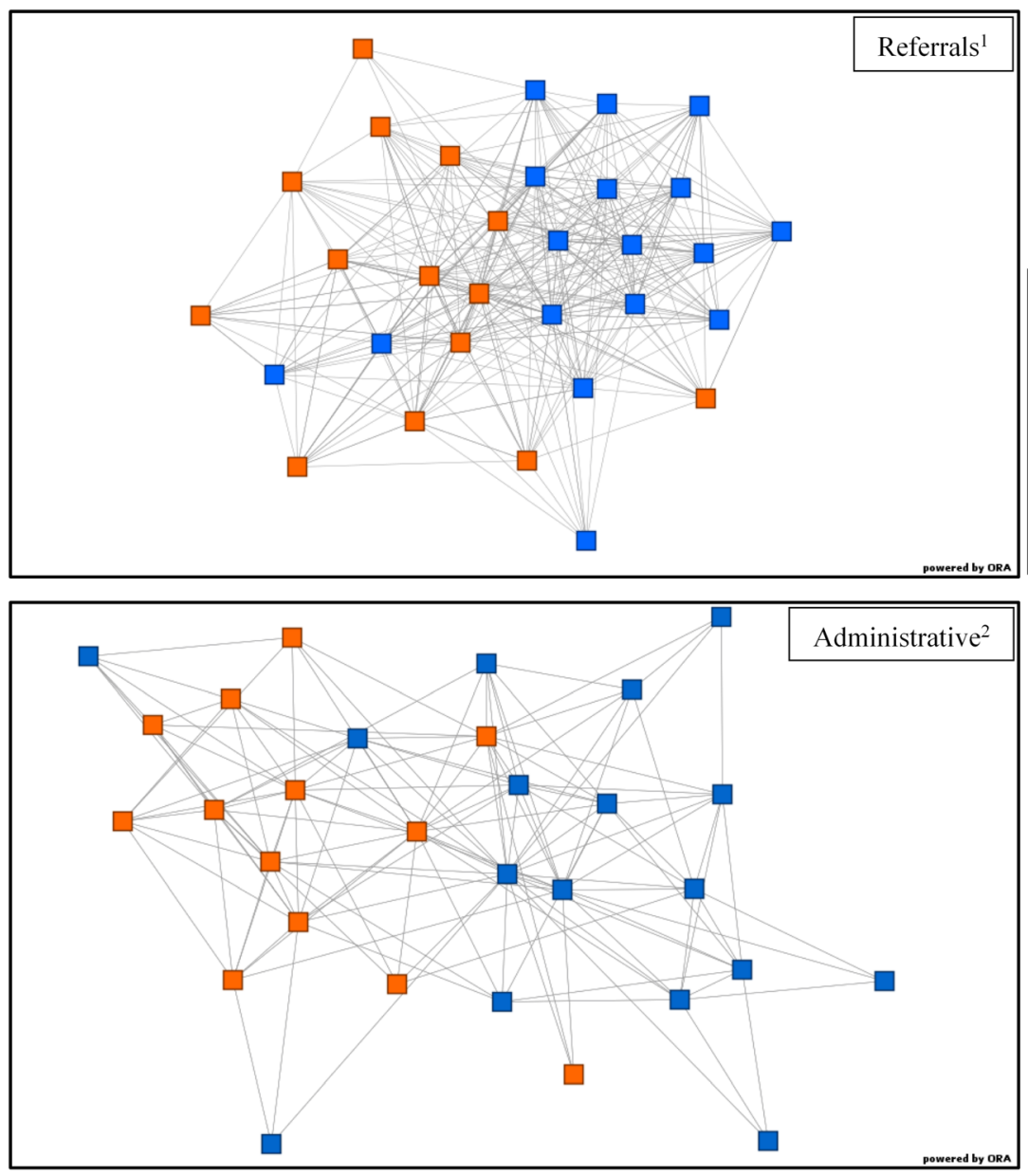

\section{Legend}

- North Philadelphia

South/Center Philadelphia

Tie between organizations ${ }^{4}$

${ }^{1}$ Organizational coordination based on referral to another organization

${ }^{2}$ Organizational coordination based on administrative coordination (e.g., - sharing staff or facilities)

3 Organizational coordination based on planning activity coordination

4 Ties displayed can be either unidirectional (e.g., - only one organization reports collaborating, but the other did not) or bidirectional (e.g., - both organizations report collaborating). Sociograms were created using a spring embedding algorithm which locates the points in such a way as to put those with smallest path lengths to one another closest in the graph.

Fig. 1 Network of Latino-serving organizations in North and South/Center Philadelphia and their collaborative linkages for referrals, administrative coordination, and planning $(N=31)$

significantly less dense than bonding ties (i.e., ties between providers within each of these geographies). Examination of bridging ties across geography showed referrals between providers in North and South/Center Philadelphia occurring at a much lower rate $(17 \%)$ than between providers within North 


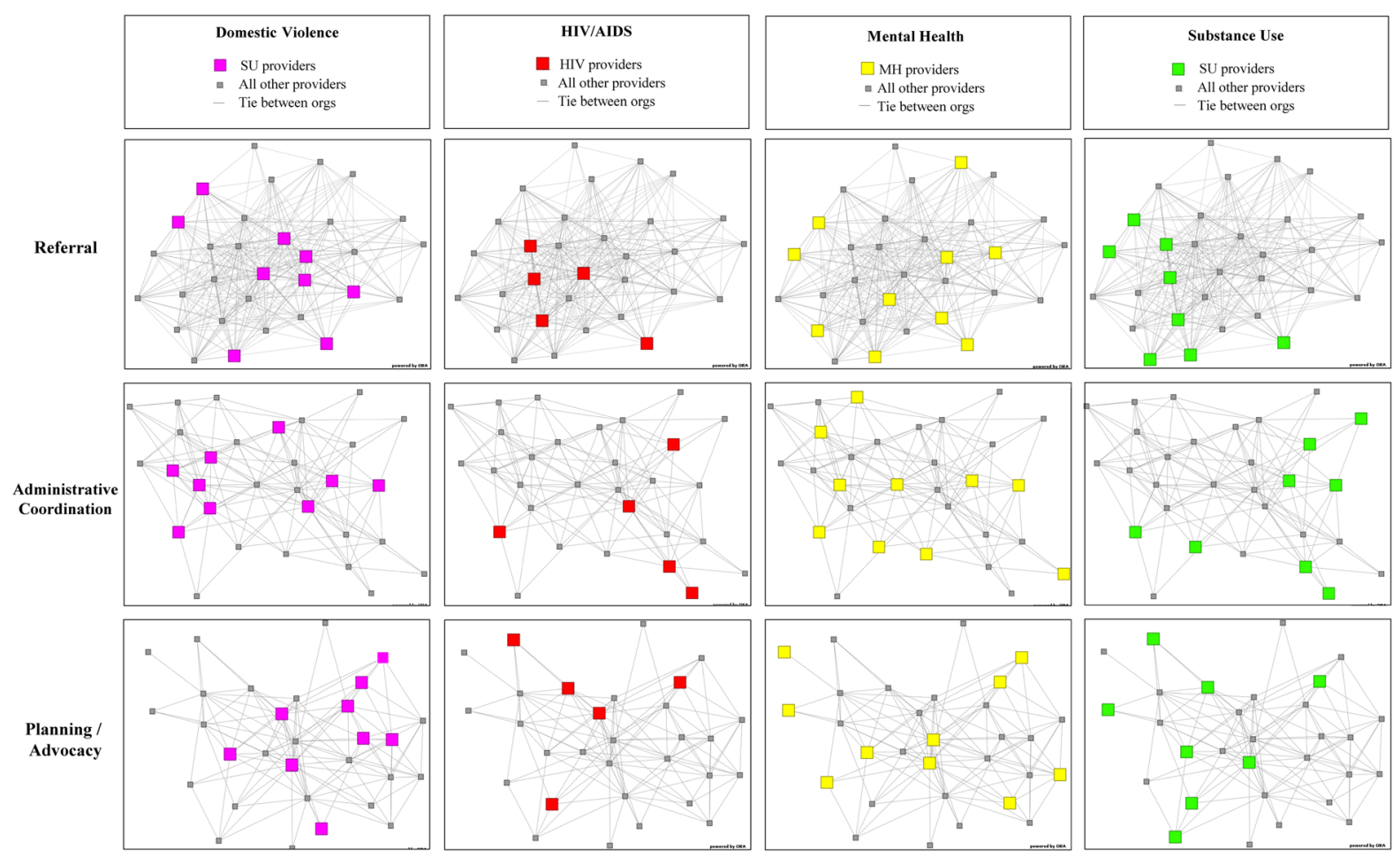

Fig. 2 Collaborative ties between Latino-serving organizations in Philadelphia by type of service provided and by type of collaboration $(N=31)$

Philadelphia (50\%) or South/Center Philadelphia (43\%). Similarly, administrative coordination (11\%) between providers in North and South/Center Philadelphia occurs at a much lower rate across geography than within each of these communities $(35 \%$ and $45 \%$, respectively). The same pattern was observed for planning activity coordination between providers in these two areas, with only $9 \%$ of possible ties reported vs. $32 \%$ within each of these areas. Finally, examination of bridging ties also suggested much lower levels of perceptions of high value between North and South/Center Philadelphia providers (24\%) than within each geography (56-57\%).

\section{Collaboration across Pairs of Syndemic Factors (Integration)}

Analyses of bridging ties across syndemic factors showed the extent of integration of SAVAME services provided by different organizations in Philadelphia (Table 2). Overall, density of bridging ties across different types of service providers was highest for high value (43\%) followed closely by referrals $(38 \%)$, compared with planning $(23 \%)$ and administrative coordination (20\%).

There was much evidence of high-value and referral activity across specific pairs of syndemic factors. HIV/AIDS and substance use providers rate each other as high-value organizations and referred to each other the most often $(57 \%$ high value and $54 \%$ referral), followed by domestic violence and mental health providers $(50 \%$ high value and $39 \%$ referral). High-value and referral rates were lowest between mental health and HIV/AIDS organizations (33\% vs. $29 \%$ ). Densities of high-value and referral bridging ties for other SAVAME pairs ranged between 42 and $30 \%$. Similar to patterns in high-value and referral networks, substance use and HIV/AIDS providers (25\% administrative and $31 \%$ planning) and domestic violence and mental health providers (28\% administrative and $31 \%$ planning) were the most integrated. Mental health and HIV/AIDS providers had the least amount of planning and administrative coordination bridging ties (13\% vs. 14\%). 
Table 2 Density and pattern of collaborative linkages and perceptions of high value between Latino-serving organizations in Philadelphia, 2018-2019 (N=31)

\begin{tabular}{|c|c|c|c|c|c|c|c|}
\hline & \multirow[t]{2}{*}{$N$} & \multicolumn{2}{|l|}{ Referral $^{1}$} & \multirow{2}{*}{$\begin{array}{l}\text { Administrative }^{2} \\
\text { Density }^{5}\end{array}$} & \multirow{2}{*}{$\begin{array}{l}\text { Planning/advocacy } \\
\\
\text { Density }^{5}\end{array}$} & \multicolumn{2}{|c|}{ High value $^{4}$} \\
\hline & & Density $^{5}$ & Reciprocity $^{6}$ & & & Density $^{5}$ & Reciprocity $^{6}$ \\
\hline Overall network & 31 & 40 & 36 & 29 & 26 & 50 & 41 \\
\hline \multicolumn{8}{|l|}{ Location } \\
\hline Bonding $^{7}$ (overall average) & & 46 & 45 & 40 & 32 & 56 & 41 \\
\hline South/Center Philly & 13 & 43 & 43 & 45 & 32 & 56 & 38 \\
\hline North Philly & 18 & 50 & 47 & 35 & 32 & 56 & 45 \\
\hline Bridging $^{8}$ (overall average) & & 17 & 25 & 11 & 9 & 22 & 39 \\
\hline North and South/Center & 31 & 17 & 25 & 11 & 9 & 22 & 39 \\
\hline \multicolumn{8}{|l|}{ Syndemic factors } \\
\hline Bonding $^{7} \quad$ (overall average) & & 59 & 49 & 37 & 38 & 66 & 49 \\
\hline Substance use & 8 & 52 & 38 & 18 & 32 & 61 & 36 \\
\hline HIV/AIDS & 5 & 85 & 70 & 50 & 40 & 75 & 67 \\
\hline Domestic violence & 9 & 64 & 59 & 53 & 53 & 71 & 55 \\
\hline Mental health & 10 & 36 & 28 & 27 & 27 & 56 & 39 \\
\hline Bridging $^{8}$ (overall average) & & 38 & 41 & 20 & 23 & 43 & 44 \\
\hline HIV/AIDS and $\mathrm{SU}^{9}$ & 9 & 54 & 60 & 25 & 31 & 57 & 46 \\
\hline $\mathrm{DV}^{10}$ and $\mathrm{MH}^{11}$ & 15 & 39 & 42 & 28 & 31 & 50 & 50 \\
\hline $\mathrm{MH}^{11}$ and $\mathrm{SU}^{9}$ & 14 & 30 & 31 & 15 & 22 & 42 & 32 \\
\hline $\mathrm{DV}^{10}$ and $\mathrm{SU}^{9}$ & 14 & 36 & 35 & 19 & 18 & 39 & 43 \\
\hline $\mathrm{DV}^{10}$ and HIV/AIDS & 12 & 38 & 39 & 23 & 24 & 37 & 53 \\
\hline $\mathrm{MH}^{11}$ and HIV/AIDS & 14 & 29 & 37 & 13 & 14 & 33 & 40 \\
\hline
\end{tabular}

\footnotetext{
${ }^{1}$ Sharing information or directing to other agencies' services, making appointments, or assisting with intake, etc.

${ }^{2}$ Jointly operating programs with another organizations, sharing staff, facilities, or training opportunities, etc.

${ }^{3}$ Partnering on grant applications, agenda-setting conversations, or advocacy about relevant issues, etc.

${ }^{4}$ Perceptions of value as reported about other organizations in the network (e.g., "This organization is highly valuable for the Latino community")

${ }^{5}$ Percent of ties in the network compared to the total possible number of ties (range $0-100 \%$ )

${ }^{6}$ Percent of mutual ties in the network compared to the total possible number of ties in the network (range $0-100 \%$ )

${ }^{7}$ Measure of how interconnected organizations are within a certain group

${ }^{8}$ Measure of how connected organizations are between certain groups

${ }^{9}$ Substance use

${ }^{10}$ Domestic violence

${ }^{11}$ Mental health
}

\section{Discussion}

This study leveraged network analytic methods to characterize the organizational landscape of Latino-serving organizations in Philadelphia and explored roles of geography and type of service offered in interorganizational collaborations. Analysis results depict a complex, interconnected network of institutions with much potential for reducing Latino health disparities related to the four SAVAME syndemic factors. Referrals and perception of high value occur and are reciprocated at high rates among Latino-serving providers in the network, suggesting relatively high levels of trust and a strong basis for future growth and strengthening of collaborative ties.

Our analyses revealed gaps and collaborative areas for improvement. Administrative coordination and planning activity coordination, which represent more 
advanced levels of collaboration, are less present in the network. Findings are consistent with integrative coordination research, which shows planning as most difficult to achieve and service delivery coordination of service delivery as most easily achieved [19]. Reasons for modest findings in integrative collaboration for administration or planning could include the greater capacity and resource investment necessary for these types of collaborations and perceived competition for clients and funding [25]. While referral rates were higher than other forms of collaboration, there is still a need for increased and improved referrals and integration of services between organizations to better meet population needs.

Consistent with anecdotal evidence and previous research regarding service providers in Philadelphia [13], our analysis revealed geographic location matters, with more ties between organizations located in or serving the same area compared to ties between organizations in different locales. However, our results also indicate some level of connection, mostly referrals, between providers in North Philadelphia and in South/Center Philadelphia, most frequently from South to North. Connections and directionality of ties may reflect more, larger, and longer-established Latino-serving organizations in North Philadelphia because this has been a Latino enclave for longer than South/Center Philadelphia [11]. Distance between these organizations and lack of location familiarity may represent a barrier for effective linkage of Latinos residents in South/Center Philadelphia to organizations in North Philadelphia. Due to gentrification, there is ongoing internal migration of Latinos from South and Central Philadelphia to North or Northeast Philadelphia. These findings are relevant as providers continue grappling with geographical barriers to reaching low-resource Latino populations.

Similarly, collaborations vary by type of syndemic factor for which an organization offers services. Substance use and mental health services seem to engage in fewer coordination efforts (lower referral, administrative coordination, and planning activity collaborative ties) than domestic violence and HIV/AIDS service providers. Furthermore, collaborations among organizations that offer complementary services are more frequent between providers of specific pairs of services, potentially due to funding sources or differing alignment of service systems city-wide. For example, bridging ties suggest strong connections between HIV/AIDS and substance use providers and between domestic violence and mental health services. This configuration makes sense given the syndemic nature of these pairs of factors (interconnections between substance use and HIV/ AIDS in Latino populations). Intravenous drug use (IDU) is associated with $20-30 \%$ of HIV infections among Puerto Ricans, one of the largest subgroups of Latinos in Philly [4]. Substance abuse also negatively affects retention into HIV care [26]. Domestic violence and other violence victimization survivors have greater mental health needs and face numerous barriers to accessing culturally appropriate mental health services [5]. However, more limited collaborations between providers of other pairs of services seem to ignore the important reciprocal influences across other pairs of syndemic factors (e.g., substance use and mental health), indicating missed opportunities to improve service coordination across providers of the four syndemic factors to better serve Latino communities in Philadelphia.

Many providers in our network of Latino-serving organizations offered SAVAME-related social services and refer frequently to legal providers. Legal support for Latino populations is critical, especially for foreign-born Latino immigrants who often have an irregular immigration status [27]. Survivors of domestic violence who are undocumented also qualify for U nonimmigrant Visas, rendering referrals and collaboration with legal providers all the more essential [28]. The inclusion of legal, educational, and other social services in the network of Latinoserving institutions in Philadelphia is consistent with the notion that successful networks evolve past a set of core services to strengthen their capacity to serve the complex social determinants of vulnerable populations [29]. It is also a potential indicator of the organic nature of service integration and consistent with national trends of providers recognizing the importance of a holistic care approach emphasizing social and environmental determinants of health [30]. Given the unique role of legal care to improve overall health outcomes among Latinos and bridge gaps in delivery of care, approaches such as medical-legal partnerships should be considered [27].

These findings have significant implications for Philadelphia-based providers and decision-makers. Results suggest greater integration of services is possible and needed to respond more effectively to the SAVAME syndemic and provide sufficient related services for Latino immigrants in Philadelphia. Interventions would build upon a strong foundation of Latino-serving organizations and their network of collaborations. Creating funding streams 
that require or incentivize collaboration between organizations which offer complementary services or serve geographically overlapping populations could promote interorganizational collaboration. Most institutional networks are determined by funding structures and current funding structures are not supportive of service integration [31]. Additional outreach to providers, especially substance use and mental health services providers, could identify barriers and opportunities for further integration into the network of Latino-serving providers. Honest, independent brokers may play a role in convening organizations and promoting institutional collaborations, and merit further research to better understand network-level interventions to promote health of populations [32].

In response to COVID-19, investigators co-authoring this publication convened bi-weekly town halls of Latinoserving organizations to respond to challenges brought about by the pandemic. Anecdotal evidence suggested that exchange of information and collective discussions among this Latino Health Collective have promoted a collaborative atmosphere among organizations and have already resulted in new and unique partnerships to advance Latino health in Philadelphia. Network analysis holds much promise for identifying areas of opportunity at the organizational- (as opposed to individual-) level to improve community health. Future research can examine how characteristics of this network evolve after implementation of community-wide interventions to promote interorganizational dialogue and collaboration around SAVAME-related services.

\section{Limitations}

This study has some important limitations. Although the response rate for the survey was high $(72.1 \%)$, the lack of response from some organizations, and the possible differences between responders and non-responders, may bias our conclusions. Organizations that agreed to participate may differ from those who declined in important ways, including their level of interorganizational collaborations with other providers in Philadelphia. Another limitation is the exclusive reliance on self-report. The organizational representative could potentially have been unaware of or unable to recall organizational ties with other Latinoserving agencies, resulting in an inaccurate representation of the true formal ties of the organization overall. However, interorganizational ties that are not institutionalized throughout the organization and thus known to most senior staff may not be as robust. Survey results could also be affected by social desirability bias, or the inclination to frame services in a more positive light due to concerns of how respondents portray the organization they represent. Finally, the results of this study may not be generalizable or extrapolated beyond the City of Philadelphia, although the methods used here can be replicated for similar resource assessments in other communities and likely related to interorganizational networks among similar urban populations.

\section{Conclusion}

Latino-serving organizations are important resources for Latino immigrants in any community and a contributing factor for community resilience. In Philadelphia, these organizations form a strong, interconnected network, but there is substantial room to further integrate services and respond to the syndemic nature of the SAVAME factors. This study leveraged network analytic methods to identify a strong network of providers in Philadelphia, despite silos based on geography and type of service offered. Referrals are the most prevalent form of collaboration, over administrative and planning activity coordination. Creating new funding mechanisms and connecting providers of different SAVAME services via independent brokers could aid in promoting integration of services and adoption of a syndemic orientation to reduce Latino health disparities in Philadelphia and, possibly, other communities in the USA.

Acknowledgements This study was supported by NIHMD \#1R21MD012352-01A1 (PI: Ana Martinez-Donate)

\section{References}

1. González-Guarda RM, Florom-Smith AL, Thomas T. A syndemic model of substance abuse, intimate partner violence, HIV infection, and mental health among Hispanics. Public Health Nurs. 2011;28(4):366-78.

2. Gonzalez JS, Hendriksen ES, Collins EM, Durán RE, Safren SA. Latinos and HIV/AIDS: examining factors related to disparity and identifying opportunities for psychosocial intervention research. AIDS Behav. 2009;13(3):582-602.

3. Guerrero EG, Marsh JC, Khachikian T, Amaro H, Vega WA. Disparities in Latino substance use, service use, and treatment: implications for culturally and evidence-based interventions under health care reform. Drug Alcohol Depend. 2013;133(3):805-13. 
4. Lewis CF, Rivera AV, Crawford ND, Gordon K, White K, Vlahov D, et al. Individual and neighborhood characteristics associated with HIV among black and Latino adults who use drugs and unaware of their HIV-positive status, New York City, 2000-2004. J Racial Ethn Health Disparities. 2016;3(4):573-81.

5. Dekker JJ, Theunissen J, Van R, Peen J, Duurkoop P, Kikkert M. Victimization of patients with severe psychiatric disorders: prevalence, risk factors, protective factors and consequences for mental health. A longitudinal study. BMC Public Health. 2010;10(1):1-5.

6. Rodríguez M, Valentine JM, Son JB, Muhammad M. Intimate partner violence and barriers to mental health care for ethnically diverse populations of women. Trauma, Violence, Abuse. 2009;10(4):358-74.

7. Singer M, Bulled N, Ostrach B, Mendenhall E. Syndemics and the biosocial conception of health. The Lancet. 2017;389(10072):941-50.

8. Lopez, G, Bialik, K, Radford, J. Key findings about U.S. immigrants. Pew Research Center. [Internet]. 2018. Available from: http://www.pewresearch.org/facttank/2018/11/30/key-findings-about-u-s-immigrants/2018 /11/30/key-findings-about-u-s-immigrants/2018/11/30/keyfindings-about-u-s-immigrants/2018/11/30/key-findingsabout-u-s-immigrants/. Accessed 24 Sept 2020.

9. U.S. Census Bureau (2019). Demographic and housing estimates, 2010-2019 American Community Survey. Retrieved from https://data.census.gov/. Accessed 24 Sept 2020.

10. Ribeiro, AM. The battle for harmony: intergroup relations between blacks and Latinos in Philadelphia, 1950s to 1980s [dissertation]. Pittsburgh (PA): University of Pittsburgh; 2013. https://core.ac.uk/download/pdf/12215021.pdf. Accessed 24 Sept 2020.

11. Giordano KR, Dsouza N, McGhee-Hassrick E, Martinez O, Martinez-Donate AP. Provider perspectives on Latino immigrants' access to resources for syndemic health issues. Hispanic Health Care Int. 2021;13:1-11.

12. Philadelphia Department of Public Health. 2016 Community Health Assessment (CHA). [Internet]. 2017. Available from: http://www.phila.gov/health/commissioner. Accessed 24 Sept 2020.

13. Pachter LM, Lieberman L, Bloom SL, Fein JA. Developing a community-wide initiative to address childhood adversity and toxic stress: a case study of the Philadelphia ACE task force. Acad Pediatrics. 2017;17(7):S130-5.

14. Varda D, Shoup JA, Miller S. A systematic review of collaboration and network research in the public affairs literature: implications for public health practice and research. Am J Public Health. 2012;102(3):564-71.

15. Stokols D. Translating social ecological theory into guidelines for community health promotion. Am J Health Promot. 1996;10(4):282-98.

16. Bronfenbrenner U. Ecological models of human development. In Gauvain, M, Cole, M, ed. Readings on the development of children. New York, NY: Worth Publishers; 1994:37-43. https://impactofspecialneeds.weebly. com/uploads/3/4/1/9/3419723/ecologial_models_of_ human_development.pdf. Accessed 24 Sept 2020.
17. Vaughn LM, Jacquez F, Marschner D, McLinden D. See what we say: using concept mapping to visualize Latino immigrant's strategies for health interventions. Int J Public Health. 2016;61(7):837-45.

18. Oliver C. Sustainable competitive advantage: combining institutional and resource-based views. Strat Manag J. 1997;18(9):697-713.

19. Bolland JM, Wilson JV. Three faces of integrative coordination: a model of interorganizational relations in community-based health and human services. Health Serv Res. 1994;29(3):341-66.

20. Mendenhall E. Syndemics: a new path for global health research. The Lancet. 2017;389(10072):889-91.

21. Luke DA, Harris JK. Network analysis in public health: history, methods, and applications. Annu Rev Public Health. 2007;28:69-93.

22. Jippes E, Achterkamp MC, Brand PL, Kiewiet DJ, Pols J, van Engelen JM. Disseminating educational innovations in health care practice: training versus social networks. Soc Sci Med. 2010;70(10):1509-17.

23. Yousefi-Nooraie R, Dobbins M, Brouwers M, Wakefield P. Information seeking for making evidence-informed decisions: a social network analysis on the staff of a public health department in Canada. BMC Health Serv Res. 2012;12(1): 118.

24. Lin N. A network theory of social capital. In Castiglione, D, van Deth, J, Wolleb, G ed. The handbook of social capital. New York, NY: Oxford University Press; 2008:50-69. http://pro-classic.com/ethnicgv/SN/SC/paper-final-041605. pdf. Accessed 24 Sept 2020.

25. Snavely K, Tracy MB. Collaboration among rural nonprofit organizations. Nonprofit Manag Leadersh. 2000;11(2):14565.

26. Levison JH, Bogart LM, Khan IF, Mejia D, Amaro H, Alegría M, et al. "Where it falls apart": barriers to retention in HIV care in Latino immigrants and migrants. AIDS Patient Care STDs. 2017;31(9):394-405.

27. Martinez O, Boles J, Muñoz-Laboy M, Levine EC, Ayamele $\mathrm{C}$, Eisenberg R, et al. Bridging health disparity gaps through the use of medical legal partnerships in patient care: a systematic review. J Law, Med Ethics. 2017;45(2):260-73.

28. Modi MN, Palmer S, Armstrong A. The role of Violence Against Women Act in addressing intimate partner violence: a public health issue. J Women's Health. 2014;23(3):253-9.

29. Provan KG, Milward HB. Do networks really work? A framework for evaluating public-sector organizational networks. Public Admin Rev. 2001;61(4):414-23.

30. Taylor LA, Tan AX, Coyle CE, Ndumele C, Rogan E, Canavan M, et al. Leveraging the social determinants of health: what works? PLoS One. 2016;11(8):e0160217.

31. Sandfort J. Nonprofits within policy fields. J Policy Anal Manag. 2010;29(3):637-44.

32. Eagly AH. When passionate advocates meet research on diversity, does the honest broker stand a chance? J Soc Issues. 2016;72(1):199-222.

Publisher's Note Springer Nature remains neutral with regard to jurisdictional claims in published maps and institutional affiliations. 